\title{
New Double Electrode System for the Electrochemical Desalination of Building Stones
}

\author{
Feijoo, Jorge; Rivas, Teresa; Nóvoa, X.R.; Ottosen, Lisbeth M.
}

Published in:

International Journal of Architectural Heritage

Link to article, DOI:

10.1080/15583058.2018.1561962

Publication date:

2020

Document Version

Peer reviewed version

Link back to DTU Orbit

Citation $(A P A)$ :

Feijoo, J., Rivas, T., Nóvoa, X. R., \& Ottosen, L. M. (2020). New Double Electrode System for the Electrochemical Desalination of Building Stones. International Journal of Architectural Heritage, 14(5), 678-693. https://doi.org/10.1080/15583058.2018.1561962

\section{General rights}

Copyright and moral rights for the publications made accessible in the public portal are retained by the authors and/or other copyright owners and it is a condition of accessing publications that users recognise and abide by the legal requirements associated with these rights.

- Users may download and print one copy of any publication from the public portal for the purpose of private study or research.

- You may not further distribute the material or use it for any profit-making activity or commercial gain

- You may freely distribute the URL identifying the publication in the public portal 


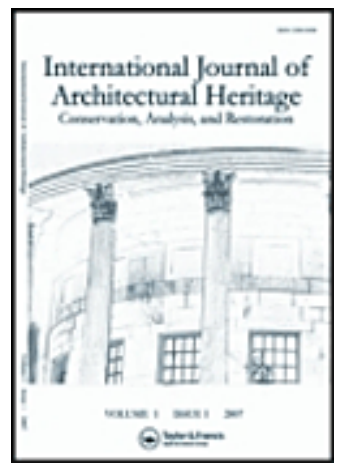

\section{New double electrode system for the electrochemical desalination of building stones}

\begin{tabular}{|r|l|}
\hline Journal: & International Journal of Architectural Heritage \\
\hline Manuscript ID & UARC-2018-2255.R1 \\
\hline Manuscript Type: & Original Article \\
\hline Date Submitted by the & $30-$ Nov-2018 \\
\hline Complete List of Authors: & $\begin{array}{l}\text { Feijoo, Jorge; Instituto de Geociencias } \\
\text { Rivas, Teresa; Universidade de Vigo, Dpto. Ingeniería de los Recursos } \\
\text { Naturales y Medio Ambiente } \\
\text { Novoa, X.R.; University of Vigo, Dep. Chem. Eng., ENCOMAT group } \\
\text { Ottosen, Lisbeth; Technical University of Denmark }\end{array}$ \\
\hline Keywords: & $\begin{array}{l}\text { Electromigration, Electroosmosis, Desalination, Sandstone, Soluble salts, } \\
\text { Double electrode }\end{array}$ \\
\hline &
\end{tabular}

\section{SCHOLARONE \\ Manuscripts}




\section{New double electrode system for the electrochemical desalination of building stones}

Jorge Feijoo*

Ph.D. Institute of Geosciences IGEO (CSIC/UCM), c/Doctor Severo Ochoa, 7, 28040, Madrid, Spain.j.feijoo@,csic.es

Teresa Rivas

Ph.D. Dep. Ingeniería de los Recursos Naturales y Medio Ambiente, Universidad de Vigo,Lagoas-Marcosendes/n,36310Vigo,Spain.trivas@uvigo.es

X.R. Nóvoa

Ph.D. Dep. Chem. Eng., ENCOMAT group, EEI. University of Vigo. 36310 Vigo-Spain, Lagoas-Marcosende s/n, 36310 Vigo, Spain.rnovoa@uvigo.es

L.M. Ottosen

Department of Civil Engineering Building 117, Technical University of Denmark, 2800 Kgs. Lyngby, Denmark.lo@byg.dtu.dk

* Corresponding author 


\begin{abstract}
:
The application of electrokinetic techniques for the mobilization and the removal of ions present in different porous materials, such as building construction materials, have shown high efficiency with respect to that reached with other techniques. However, some drawbacks related mainly with the mobilization efficiency of the ions of interest and with the integrity of the porous material due to the possible chemical and/or aesthetic damages have still to be overcome to take advantage of the full potentiality of these techniques. To overcome these limitations the present study evaluates the effectiveness of a new electrokinetic configuration based on the use of two electrodes per compartment that allow modulating the net amount of $\mathrm{OH}^{-}$and $\mathrm{H}^{+}$groups produced at the electrodes' surface. This effectiveness was evaluated desalinating sandstone samples contaminated with different salts. The results indicate that the new configuration allowed: maintaining a high moisture content, both in poultices and stones, which allowed the treatment to work properly for longer time; to reach high percentages of reduction of all the ions present in the treated stones; to effectively buffer the $\mathrm{pH}$ variations due to the possibility of modulate the net amount of $\mathrm{OH}^{-}$and $\mathrm{H}^{+}$groups produced.
\end{abstract}

Keywords: Electromigration, electroosmosis, desalination, sandstone, soluble salts, double electrode

\title{
1. Introduction
}

Electrokinetic techniques have shown high efficiency in the mobilization of ions present in porous materials and have been applied for that purpose in several fields, such as the extraction of heavy metals in contaminated soils (Jeon et al. 2015) (Ottosen et al. 2001, 2005) (Yeung and Gu 2011), the recovery of contaminants as the phosphorus present in sewage sludge (Guedes et al. 2014) (Ottosen, Kirkelund and Jensen, 2013) (Parés Viader 
et al. 2015) (Sturm et al. 2010) or metals present in waste dumps (Hansen, Rojo and Ottosen 2012) (Idris, Inanc and Hassan 2004) (Pedersen, Ottosen and Villumsen 2005). The removal of soluble salts present in porous materials used in building construction such as concrete (Orellan, Escadeillas and Arliguie 2004) (Polder 1996) (Shan et al. 2016), bricks (Ottosen, Rörig-Dalgaard and Villumsen 2008) (Ottosen, and RörigDalgaard 2009), ceramic (Ottosen, Ferreira and Christensen 2010) or ornamental rocks (granite (Feijoo et al. 2013, 2018a) (Feijoo, Ottosen and Pozo-Antonio 2015), sandstone (Feijoo et al. 2016) (Matyscak, Ottosen, and Rörig-Dalgaard 2014) (Ottosen and Christensen 2012), limestone (Ottosen, Christensen and Rörig-Dalgaard 2012)) represents also a very large domain of application. In this field (intervention of building materials), the efficiency showed by this technique in different porous materials (which can be consulted in the studies mentioned above) is higher than that achieved by other desalination techniques such as: immersion baths in water (Koob and Yee Ng 2000) (Unhruh 2001), use of crystallization inhibitors (Lubelli and van Hess 2007) (Rivas et al. 2017), application of poultices (Lubelli and van Hess 2010) (Lubelli, van Hess and De Clercq 2011) (Vergès-Belmin and Siedel 2005) or sacrificial mortars (Setina et al. 2009) (Husillos-Rodríguez et al. 2018), among others.

The operation of the electrokinetic techniques has two main limitations that affect the mobilization efficiency of the ions of interest:

1) The entrance into the medium to be treated of a high quantity of $\mathrm{OH}^{-}$and $\mathrm{H}^{+}$formed at electrodes by water reduction and oxidation, respectively. These species are about one order of magnitude more mobile than the other ions (Ottosen et al. 2008) (Rörig-Dalgaard 2012) (Sa'id-Shawqi, Arya and Vassie 1998) which causes decreased current efficiency towards mobilization of the ions of interest (Castellote, Andrade and Alonso 2000) (Feijoo, Ottosen and Pozo-Antonio 2015) (Kamran et al. 2012) (Rörig-Dalgaard 2012). 
2) The differential drying process that occurs in the vicinity of one of the electrodes, which restricts or hinders the flow of the electric current through the material, resulting in reduction of the operating time (Ottosen, Rörig-Dalgaard and Villumsen 2008) (Ottosen, Pedersen and Rörig-Dalgaard 2007) (Ottosen and Rörig-Dalgaard 2007). This fact, due to the establishment of an electroosmotic flux, hinders the contact between the current-driven electrode and the surrounding material. The direction of the electroosmotic flux depends on the surface charge of the pores network of the material through which the electric current flows (Asadi et al. 2013) (Ottosen et al. 2008). As the surface charge of most construction materials is negative, the electroosmotic flux tends to hydrate the material located at the cathode (Bertolini et al. 2009) (Franzoni 2014) (Franzoni, Bandini and Graziani 2014).

Desalination of porous materials used in construction, especially those used in monuments catalogued as cultural heritage, faces some limitations. One of them particularly relevant is the possibility of chemical alteration of rock forming minerals or chemical compounds present in construction materials because of their exposure to extreme $\mathrm{pH}$ values generated during the electrokinetic treatment. These extreme $\mathrm{pH}$ values (acidification and alkalinization) occur at the vicinity of the electrodes (anode and cathode respectively) due to the water hydrolysis (Auras and Albertsen 2008) (Feijoo et al. 2013) (Feijoo, Ottosen and Pozo-Antonio 2015) (Ottosen et al. 2008) (Rörig-Dalgaard, Ottosen and Hansen 2012), according to Eq. 1 and Eq. 2.

At the anode: $\mathrm{H}_{2} \mathrm{O} \rightarrow 1 / 2 \mathrm{O}_{2(\mathrm{~g})}+2 \mathrm{H}^{+}+2 \mathrm{e}^{-}$

At the cathode: $2 \mathrm{H}_{2} \mathrm{O}+2 \mathrm{e}^{-} \rightarrow 2 \mathrm{OH}^{-}+\mathrm{H}_{2(\mathrm{~g})}$

A second limitation is the possibility of altering the aesthetic value of the materials due to color changes. These color changes are usually associated with changes in the oxidation 
state of some chemical elements present in the materials composition, such as $\mathrm{Fe}^{\mathrm{z}}$ or $\mathrm{Mn}^{\mathrm{z}}$, mainly in the vicinity of the anode (Auras and Albertsen 2008). $\mathrm{Fe}^{2+}$ and $\mathrm{Mn}^{2+}$ are stable in acidic media, but tend to oxidize at neutral to alkaline $\mathrm{pH}$ values.

In a previous study (Feijoo et al. 2018b) the effectiveness of a new electrokinetic setup based on the use of two electrodes at the anode, between which different potentials were applied was analyzed. This device, validated during the extraction of soluble salts from a sandstone, allowed the establishment of an electro-osmotic process at the anode that increased the duration of the conventional electrokinetic procedure (i.e. using a unique electrode at the cathode and at the anode). The double-anode setup improved also the $\mathrm{pH}$ buffering capacity at the anode and increased the effectiveness of the conventional desalination treatment due to reduction of the $\mathrm{H}^{+}$concentration in the vicinity of the stone. However, a high $\mathrm{pH}$ values were observed at the cathode which could limit the application of this setup in certain cases because:

a) The treated material could be affected by alkaline $\mathrm{pH}$ values.

b) The probable entrance of a higher fraction of $\mathrm{OH}^{-}$ions in the material will reduce the effectiveness of the treatment.

The present study aims at evaluating the efficiency (in terms of percentage of removal of ions, in this case soluble salts) and the behavior (in terms of water content and $\mathrm{pH}$ buffering capacity) of a new electrokinetic configuration based on the use of two electrodes per compartment. The effectiveness of this new double electrode device is evaluated comparatively to a configuration with two electrodes only at the anode (the set up tested in (Feijoo et al. 2018b)) and to another configuration with two electrodes at the cathodic compartment. Different potentials will be applied between electrodes of the same compartments in all setups. 


\section{Materials and Methods}

\subsection{The porous material}

An ashlar of sandstone extracted from the Kronborg castle located in Helsingor (Denmark) was used for this study; this castle was declared as a World Heritage Site by UNESCO in 2000.

The mineralogical and chemical composition and the main physical properties of the sandstone (accessible porosity of water, water absorption coefficient, capillary porosity, tortuosity, zeta potential...) are detailed in previous researches (Feijoo et al. 2016, 2017 and 2018b). Briefly, the most relevant characteristics of this rock are the following:

1) It is a very fine grained sandstone, composed mainly by subangular quartz grains (50$100 \mu \mathrm{m})$ cemented by kaolinite plates. The main major chemical elements are $\mathrm{SiO}_{2}$ $(95.07 \%)$ and $\mathrm{Al}_{2} \mathrm{O}_{3}(3.26 \%)$ with a low content of $\mathrm{CaO}(0.418 \%)$, $\mathrm{TiO} 2(0.323 \%)$, $\mathrm{K}_{2} \mathrm{O}(0.203 \%), \mathrm{Fe}_{2} \mathrm{O}_{3}(0.177 \%)$ and $\mathrm{Na}_{2} \mathrm{O}(0.15 \%)$.

2) The accessible porosity to water is $13.24 \%$ and to mercury is $17.30 \%$. This difference indicates that this rock has a certain pore volume hardly accessible to water.

3) The saturation degree by immersion is close to $100 \%$, which indicates that the pore connectivity of this rock is high.

4) Most pores lie in the capillary range ( $80 \%$ of the pore volume), which corresponds to pores between $0.1-100 \mu \mathrm{m}$ (Meng 1994), being its capillary porosity $11.47 \%$.

5) The zeta potential value of this stone (i.e., the surface charge of its porous network) is negative $(-24 \mathrm{mV})$; this negative charge will favor the transport of cations, as it occurs 
for cation selective membranes (Tanaka 2007), so it is expected that the electroosmotic process will occur towards the cathode.

In this study 12 stone prisms of $6 \times 6 \times 3 \mathrm{~cm}^{3}$ of this sandstone were used. In order to analyze the effectiveness of the electrokinetic technique to extract salts with different mobility, all the prisms were contaminated with a saline solution composed of $9.9 \% \mathrm{NaNO}_{3}, 6.6 \%$ $\mathrm{NaCl}$ and $0.66 \% \mathrm{CaSO}_{4}$ in weight. Before the contamination, the samples faces were marked in order to guarantee equal orientation during the contamination process and that the same parts of the rock were later compared throughout the study to calculate the extraction efficacy. The contamination process consisted in subjecting the stone prisms to periodic cycles ( 7 cycles in total) which consisted of 3 days of capillary absorption followed by 2 days of drying at room temperature. The face of the rock in contact with the saline solution was changed every cycle, in order to try to get a homogeneous distribution of the salts within the stones.

At the end of this contamination process, three of these stone prisms were used to determine the initial ion content, the reference values. For this purpose, the stone prisms were segmented into the 4 pieces previously labeled by hammer and chisel, weighed and crushed using a pulverizer ring mill; three representative samples of $10 \mathrm{~g}$ each were obtained for every crushed piece. Each sample of $10 \mathrm{~g}$ was stirred in $25 \mathrm{~mL}$ of distilled water during $24 \mathrm{~h}$ and filtered under vacuum through $0.45 \mu \mathrm{m}$ nitrocellulose filter, obtaining an aqueous extract per sample. In this aqueous extract, $\mathrm{pH}$ was measured $(\mathrm{pH}-$ meter BASIC20) and the $\mathrm{Cl}^{-}, \mathrm{SO}_{4}{ }^{2-}$ and $\mathrm{NO}_{3}{ }^{-}$contents were obtained by high resolution chromatography using a Dionex ICS-100 chromatograph.

The initial average ion content, in $\mathrm{mg} / \mathrm{g}$ were: $\mathrm{Cl}^{-}: 1160.71 \pm 56.77 ; \mathrm{SO}_{4}{ }^{2-}: 90.19 \pm 7.57$; $\mathrm{NO}_{3}: 2195.50 \pm 113.53$. The low deviation between the ion content for the pieces of the 
three reference stone prisms demonstrate that the salts are homogenously distributed throughout the whole sample and also that the initial ion content is representative to the rest of the stone prisms.

The rest of the stone prisms (9 prisms) were desalinated using three different setups ( 3 prisms per setup) according to the procedures detailed in the next section.

\subsection{Electrochemical setups. Description}

Three different setups were evaluated. The first one is called in this study "DAC-S" (Double Anode and Cathode setup) and it has two electrodes per compartment, two at the cathode and two at the anode. The second setup evaluated is called "TE-A" (Two Electrode at the Anode) and it has two electrodes in the anodic compartment and only one electrode in the cathodic compartment (Fig. 1); this setup is similar to that evaluated in (Feijoo et al. 2018b). The third setup evaluated in this study is called "TE-C" (Two Electrodes at the Cathode) and it has two electrodes in the cathodic compartment and only one in the anodic compartment. As it can be seen in Fig. 1, the DAC-S setup results from merging of the other two setups, TE-A and TE-C.

\section{INSERT FIGURE 1}

The compartments containing two electrodes consist of two media separated by a cellulose filter. The media labeled in Fig. 1 M1 and M2 correspond to the anodic side, and M3 and M4 to the cathodic side. These media differ on the composition of the poultice filling each compartment, and on the potential established at the electrode hosted therein (Fig. 2).

INSERT FIGURE 2 
The medium M1 is filled with a poultice (PA1) composed of cellulose and an electrolyte of citric acid and sodium citrate buffered at $\mathrm{pH} 6$ in a weight ratio of 1:7.6. This composition was selected, as mentioned in (Feijoo et al. 2018b), because cellulose has a high liquid storage capacity but no $\mathrm{pH}$ buffering capacity, which would allow a large amount of $\mathrm{H}^{+}$ions to be generated in the vicinity of the electrode 1 . In this electrode $1 \mathrm{a}$ potential drop $\mathrm{V}_{1}$ of $2 \mathrm{~V}$ with respect to the electrode 2 was established by means the power supply 1 . The electrode 1 was used only in the setups TE-A and DAC-S and was set at potential $\mathrm{V}_{1}+\mathrm{V}_{2}$ and $\mathrm{V}_{1}+\mathrm{V}_{2}+\mathrm{V}_{3}$ respectively, depending on the setup used. Therefore, the electrode 1 can be considered, in these setups, as the effective anode.

A second medium (called M2) is filled with a poultice (PA2) composed of kaolin, calcium carbonate and citrate/citric acid electrolyte buffered at $\mathrm{pH}$ 6. The three components in a weight ratio 1:2:1.3 respectively. This composition is the same as the used in (Feijoo et al. 2018b). The addition of calcium carbonate is the conventional way in order to buffer the acid $\mathrm{pH}$ and it is based on the decomposition of calcium carbonate at acidic $\mathrm{pH}$ according to Eq. 3, followed by reaction of the carbonate ions with the $\mathrm{H}^{+}$generating $\mathrm{CO}_{2}$ and $\mathrm{H}_{2} \mathrm{O}$ (Eq. 4). In the PA2 poultice the electrode 2 was inserted, stablishing a constant voltage $\mathrm{V}_{2}$ of $10 \mathrm{~V}$ using the power supply 2 . In TE-A and DAC-S setups, the electrode 2 behaves as bipolar electrode because it acts as anode with respect to the electrode 3 and as cathode respect to the electrode 1 . In TE-C setup, this electrode behaves as the effective anode.

$$
\begin{aligned}
& \mathrm{CaCO}_{3}+\mathrm{H}^{+} \rightarrow \mathrm{Ca}^{2+}+\mathrm{HCO}_{3}^{-} \\
& \mathrm{HCO}_{3}^{-}+\mathrm{H}^{+-} \rightarrow \mathrm{CO}_{2}(\mathrm{~g})
\end{aligned}
$$

These two media, M1 and M2, constitute the anodic compartment in the setups TE-A and DAC-S. In the setup TE-C, the anodic compartment was formed only by the medium M2. 
In the cathodic compartment, another two media, M3 and M4, were used depending on the setup (Figs. 1 and 2). The M3 medium is placed close to the material to be treated, this medium was filled with a poultice (PC2) made of kaolin and citrate/citric acid electrolyte buffered at $\mathrm{pH} 6$ in a weight ratio of 1.6:1. As mentioned in (Feijoo et al. 2018b), kaolin was selected by its ion exchange capacity, which allow to retain the $\mathrm{OH}^{-}$ ions generated in this compartment. In this medium, electrode 3 was inserted. In the setups TE-C and DAC-S a constant voltage of $1 \mathrm{~V}$ was stablished using the power supply 3, whereas in the setup TE-A 0V potential was stablished. In consequence, this electrode can behave as bipolar electrode (in TE-C and DAC-S) or as effective cathode (in TE-A) depending on the setup used.

The other medium in the cathodic side, M4, was filled with a poultice (PC1) made of kaolin, calcium carbonate and citrate/citric acid electrolyte buffered at $\mathrm{pH}$ 5. This acidic $\mathrm{pH}$ value was selected in this case in order to favor the dissolution of calcium carbonate: the calcium ions released can react with the $\mathrm{OH}^{-}$ions generated at the electrode surface, favoring in this way the $\mathrm{OH}^{-}$immobilization via precipitation of $\mathrm{Ca}(\mathrm{OH})_{2}$ (Ottosen, Ferreira and Christensen 2010). In this medium, the electrode 4 was inserted and a voltage of $0 \mathrm{~V}$ was established, behaving therefore as the effective cathode.

These two media, M3 and M4, constituted the cathode compartment in setups TE-C and DAC-S. While, in the setup TE-A, only the medium M3 formed the cathode compartment. All the electrodes used were made of titanium-MMO mesh (titanium coated with mixed metal oxides) because of its inertness against oxidation reactions.

The stone prisms were wrapped with polyethylene film to hinder evaporation through the faces parallel to the current flux. 
The application time of each setup lasted 16 days. Tests with each setup were performed in triplicate using for this purpose 3 stone prisms contaminated with the saline solution described above.

\subsection{Operation of the setups}

The three setups proposed in this study base their operation on the idea of bipolar electrodes, where a series of bars inserted in a medium are asymmetrically polarized when two external electrodes are connected to a power supply (Hansen, Rojo and Ottosen 2012) (Mavré et al. 2010). Due to these polarization processes one of the surfaces of the bars will act as the cathode of the positive electrode and the other surface will act as the anode of the negative electrode. However, unlike the setups proposed in this study, the use of bipolar electrodes does not allow to control the degree of polarization of the bars.

In the three setups, it is possible to regulate the variation of proton concentration $\Delta\left[\mathrm{H}^{+}\right]$ generated at the surface of each electrode. This variation, according Faradys' law and Eq. 5-7, depends on the circulated charge and therefore on the current intensity and time.

At electrode 1: $\Delta\left[\mathrm{H}^{+}\right]=\mathrm{Q}_{1} / \mathrm{F} \mathrm{w}=\mathrm{I}_{1} \mathrm{t} / \mathrm{F} \mathrm{w}$

At electrode 2: $\Delta\left[\mathrm{H}^{+}\right]=\mathrm{Q}_{2} / \mathrm{F} \mathrm{w}=\left(\mathrm{I}_{2}-\mathrm{I}_{1}\right) \mathrm{t} / \mathrm{F}$ w

At electrode 3: $\Delta\left[\mathrm{H}^{+}\right]=\mathrm{Q}_{3} / \mathrm{F} \mathrm{w}=\left(\mathrm{I}_{3}-\mathrm{I}_{2}\right) \mathrm{t} / \mathrm{F} \mathrm{w}$

Being Q the circulating charge in C; F the Faraday's constant $(96485 \mathrm{C} / \mathrm{mol})$, w the volume of the compartment, I the circulating current in A and t the time elapsed in s. 
Taking into account these equations, it is expected that in the setups with two electrodes hosted in the anodic compartment (TE-A and DAC-S), the following effects will occur at the electrode 2 (Fig. 3):

- Generation of water molecules due to the reaction of the generated $\mathrm{H}^{+}$, mainly at the electrode 1 , and the $\mathrm{OH}^{-}$generated at the electrode 2.

- Self-buffering capacity of the acidic $\mathrm{pH}$ at the anode because of the local $\mathrm{OH}$ production due to $\mathrm{I}_{1}$ flow (Fig. 2).

- High desalination effectiveness due to the reduction of the $\mathrm{H}^{+}$amount that enter into the stone.

- Decreasing of the amount of $\mathrm{Ca}^{2+}$ released from the decomposition of the poultice PA2, which reduces the probability of clogging some of the pores of the stone by $\mathrm{Ca}(\mathrm{OH})_{2}$ precipitation.

All these effects have already been described in a previous study (Feijoo et al. 2018b).

\section{INSERT FIGURE 3}

In the setups with two electrodes hosted in the cathodic compartment (TE-C and DACS), it is expected that the following effects occur at the electrode 3 :

- Generation of water molecules due to the same reason mentioned above.

- Self-buffering capacity of the basic $\mathrm{pH}$ at the cathode due to the neutralization of the $\mathrm{OH}^{-}$ions (generated at the electrode 4), with the $\mathrm{H}^{+}$ions generated at the electrode 3.

- High desalination effectiveness due to the reduction of the $\mathrm{OH}^{-}$amount that enter into the stone. This reduction is increased using the poultice PC1 made of kaolin, calcium carbonate and electrolyte at $\mathrm{pH} 5$ in the $\mathrm{M} 4$ medium. At this $\mathrm{pH}$ value it 
is expected that the release of calcium occurs and consequently part of the calcium will fix the $\mathrm{OH}^{-}$generated, forming $\mathrm{Ca}(\mathrm{OH})_{2}$.

Furthermore, from the previous equations it is possible to modulate the process and determine what current density it is necessary to apply, at each electrode, to reach a certain $\mathrm{pH}$ in each medium, for example to maintain the $\mathrm{pH}$ at 7 it would be necessary to apply the same current density at the three electrodes.

\subsection{Methods for effectiveness evaluation}

The total current intensity flowing into the circuit was periodically registered during the tests. Daily measurements were taken every 30 minutes during a time interval of $8 \mathrm{~h}$ by measuring the voltage drop that occurred in a resistance of $1 \mathrm{k} \Omega$ connected in series to the setup (Fig. 2). The current intensity flowing through each of the media, i.e. between the electrodes, was recorded directly from the respective power supply in the same time intervals. For the setups TE-A and TE-C two power supplies were employed, however in the setup DAC-S three power supplies were necessary (Fig. 2).

At the end of each test, each poultice was divided in three slices: A (the one closest to the anode), B (the intermediate portion) and $\mathrm{C}$ (the one closest to the cathode). Also, each sandstone prism was divided by chisel and hammer in the four parts previously marked: 1 and 2 (the closest to the anode) and 3 and 4 (the closest to the cathode) (Fig. 1).

In all of these poultice slices and sandstone parts, the following parameters were evaluated:

a) The water content (in $\% \mathrm{~g} / \mathrm{g}$ ). This was aimed at evaluate whether an electroosmotic process could take place. This parameter was calculated as the 
water content in the wet material with respect to the dry weight of the same material (poultice or stone). The dry weights were obtained after oven drying the poultice slices and stone parts at $105^{\circ} \mathrm{C}$ for 24 hours, except the cellulose poultices which were dried at $50^{\circ} \mathrm{C}$ for 3 days.

Water content $=100 *($ Weight of the wet material - Weight of the dry material $)$ / Weight of the wet material

The water content in the poultices was calculated before and after the treatment. For the stones the water content only was calculated at the end of the tests.

b) The $\mathrm{pH}$ of the aqueous extract. The $\mathrm{pH}$ was determined after stirring of $10 \mathrm{~g}$ of each sample (poultices slices or stone parts) in $25 \mathrm{~mL}$ for $24 \mathrm{~h}$, and further filtering through $0.45 \mu \mathrm{m}$ mesh nitrocellulose filters. Three replicates were used for each fraction. For cellulose samples, $1 \mathrm{~g}$ instead $10 \mathrm{~g}$ was used.

c) The ion content retained in each poultice and in the four stones parts. These measurements were performed by triplicate following the above described method. The efficacy of the desalination treatment (E\%-ion), considered as the percentage of ion reduction achieved in the sandstone prisms, was calculated using the expression used in several researches (Feijoo et al. 2016, 2018a) (Lubelli, van Hess and De Clercq 2011) (Rivas et al. 2017):

$\mathrm{E} \%-$ ion $_{1-4}=100 *(\text { Initial ion content }- \text { Final ion content })_{1-4} /$ Initial ion content $_{1-4}$

\section{Results and Discussion}

\subsection{Resistance and current intensity}

Figure 4 shows the evolution of the total resistance and the total current intensity for the different setups evaluated in this study. There is a certain similarity between the 
measurements recorded with the TE-A setup and with the DAC-S setup. In these two setups, the current intensity flowing through the stone prisms was higher than that recorded with the TE-C setup. Moreover, both records show similar trend with a nearly constant plateau during the first 200 hours of operation followed by a decreasing period of 200 more hours where the current decreases from $6 \mathrm{~mA}$ to approximately $2.5 \mathrm{~mA}$. During the test, the total current intensity value obtained in the DAC-S setup was slightly higher than that obtained in the TE-A setup. The behavior of the resistance was, logically, the inverse.

The distinct behavior observed between the three setups applied to the same sandstone (especially between the DAC-S and TE-A with respect to TE-C) cannot be attributed to differences in material's porosity, since all the samples were contaminated under the same environmental conditions $\left(\mathrm{T}^{\mathrm{a}}, \mathrm{RH}\right)$ an following the same procedure, which caused a homogeneous distribution of the salts in the whole sample, as it was verified when the different parts of the three reference samples were analyzed. Alternate interpretations have to be proposed. One possibility lies on the differential current effectiveness when the salts are forced to migrate towards the electrodes. A greater mobilization of the ions implies a greater transport of electric current, measured as a lower resistance. In this sense, the current intensity registered indicates that the TE-A and especially DAC-S setups are more effective than the TE-C. Another possibility concerns the differential water content in the poultices located in the different media or in the sandstone prisms. A low moisture content in any of these materials can hinder and even prevent the current circulation. In this sense, the evolution of the current intensity during the test seems to indicate again that the TE-A and especially DAC-S setups are able to hinder the drying process to a greater extent than the TE-C. This drying process, taking into account the $\mathrm{Z}$ potential of this rock, occurs preferably in the anode zone. In this zone, as shown in 
(Feijoo et al. 2018b), the use of 2 electrodes should allow the generation of water molecules that tend to hydrate the poultice PA2 and also to improve the contact between the electrode 2 and the PA2 poultice. In the TE-C setup, with a single electrode at the anode, the poultice PA2 tends to dry out and therefore the initially good contact between electrode-poultice tends to fade away. This fact was verified during the application of this setup, since periodic stirring up of electrode 2 was necessary to improve the ionic contact with the poultice. These actions were registered in the intensity and resistance records as marked fluctuations.

\section{INSERT FIGURE 4}

\subsection{Water content}

Table 1 shows the initial and final water content in the poultices and also the final water content in the sandstone prisms after application of the treatment according to the three setups tested.

The results obtained in the poultices are different depending on the setup used. With TE-A setup the highest reduction in water content occurs in the poultice PA1, composed of cellulose. This is due to the high initial water content of this poultice and also to the establishment of an electroosmotic process between electrode 1 and 2 which tends to increase water content at poultice PA2 while drying of poultice PA1, as demonstrated in a previous study (Feijoo et al. 2018b). The reduction of the water content achieved in the poultice PA2 was close to $12 \%$, a value closer to the reduction achieved in the cathode poultice PC2 than that obtained in the anode poultice PA1.

INSERT TABLE 1 
In the TE-C setup, the highest reduction in water content occurred in the poultice PC2 located in the medium M3. This is because the electrode 3 hosted in this medium acts as an anode with respect to the electrode 4 hosted in the medium M4, where a small percentage of reduction was observed. This result seems to indicate that an electroosmotic process took place between both electrodes that tends to hydrate the poultice PC1 and to dry the poultice PC2. The establishment of electroosmotic processes in clays is a wellkwon phenomenon (Grundl and Michalski 1996). At the anode, the water content that remains in the poultice PA2 was smaller than that remaining in the same poultice of the TE-A setup. The lower water content present in the poultices PA2 and PC2 (which were in contact with the stone), with respect to the water content of the same poultices in the TE-A setup, explains, as indicated in the previous section, why the amount of current flowing through the system was lower than that registered with the setup TE-A.

In the DAC-S setup, the highest reduction in water content in the anodic compartment occurred in the medium M1, as observed for the TE-A setup, while in the cathodic compartment the highest reduction in water occurred in the medium M3, as observed for the TE-C setup. This fact suggests that in both compartments a process of hydration of the poultices that hosted the electrodes with smaller potential (electrode 2 at the anode and electrode 4 at the cathode) took place. In the media closest to the stone prisms, M2 and M3, the percentages of reduction in water content were low and similar. These low water loss ensure that the wetting process of the stone prisms by the poultices can continue. The low percentage of reduction achieved in the poultice hosted in the medium M4 (effective cathode of the system) is a faithful reflection of the impact of the wetting process by electroosmosis.

Regarding the water content in the sandstones samples, after the 16 days of the test, the highest water content was achieved in the samples desalinated with the DAC-S setup and 
the lowest with the TE-C setup. The water content that remained in the stones desalinated with the DAC-S setup was approximately $75 \%$ higher than that remained in the samples desalinated with the TE-C setup and approximately $60 \%$ higher than that remained in the samples desalinated with the TE-A setup.

As mentioned in the previous section, the highest water content, both in poultices (especially in those located close to the stone) and in the stone prisms, improves the contact electrode-poultice and in consequence favors the current flow lowering the resistance associated to the assembly (poultices and stone).

\section{3. pH measurements}

Figure 5 shows the $\mathrm{pH}$ average values measured in aqueous extracts of the poultice slices (A, B and C) hosted in the different media (M1, M2, M3 and M4) and of the stone parts (from 1 to 4 ).

\section{INSERT FIGURE 5}

Using the TE-A setup, the $\mathrm{pH}$ values reached in the medium M1 were extremely acid (below 2). This fact is due to the high quantity of $\mathrm{H}^{+}$ions generated in this medium and to the null buffering capacity of $\mathrm{pH}$ afforded by cellulose. In the medium $\mathrm{M} 2$ the $\mathrm{pH}$ increased, exceeding the value of 8 . This increase was more noticeable in the slice $\mathrm{C}$, in which the electrode 2 was located, where the $\mathrm{pH}$ value reached was above 10 . These alkaline $\mathrm{pH}$ values, due to generation of $\mathrm{OH}^{-}$ions at electrode 2 can be related with the unreacted $\mathrm{CaCO}_{3}$ that remains in the PA2 poultice. The $\mathrm{CaCO}_{3}$ present in the contact zone between the media M1 and M2 decomposes to acid $\mathrm{pH}$ values, releasing calcium that tends to fix the $\mathrm{OH}^{-}$ions generated in the vicinity of the electrode 2 (Ottosen, Ferreira 
and Christensen 2010). The $\mathrm{pH}$ of the sandstone prisms was alkaline after desalination, ranging from 9 (in the parts close to the anode), to 11 (in the parts close to the cathode medium M3). In the medium M3, high $\mathrm{pH}$ values were reached (slightly higher than 11). These results are similar to those obtained in (Feijoo et al. 2018b).

Regarding the TE-C setup, the results were different. At the anode (medium M2) the pH values did not exceed 8, being therefore lower than those reached with the TE-A setup. This fact could be related with the buffering process associated to the decomposition of the $\mathrm{CaCO}_{3}$ present in the poultice PA2. Therefore the reduction in the $\mathrm{CaCO}_{3}$ content of the poultice PA2 and the non-generation of $\mathrm{OH}^{-}$ions in this compartment, since there is not any bipolar electrode, are the main reasons that can justify these $\mathrm{pH}$ values. With respect to the $\mathrm{pH}$ in the sandstone prisms, the parts closest to the anode (parts 1 and 2) showed $\mathrm{pH}$ values slightly lower than the $\mathrm{pH}$ values reached in the slice $\mathrm{C}$ of the poultice located in the medium M2 (ranging from 7.30 to 7.55), and similar to the characteristic $\mathrm{pH}$ of the untreated sandstone (7.15). The $\mathrm{pH}$ in the parts closest to the cathode (parts 3 and 4) showed high $\mathrm{pH}$ values (ranging from 8.20 to 9.45), which in any case were slightly lower than those reached in the cathode medium M3 (ranged from 9.70 to 10.80). At the cathode, the $\mathrm{pH}$ values were alkaline in both media, being slightly higher in the medium M4 (values close to 11). This fact is the expected considering that in this medium is located the electrode with zero potential (electrode 4), which acts as the true cathode of the setup.

Compared with the TE-A setup, the use of a second electrode in the cathode allow to reduce the amount of free $\mathrm{OH}^{-}$ions that reach the vicinity of the stone (medium $\mathrm{M} 3$ ), and in consequence hinder the alkalization process that occurs at the cathode medium M3. This is due to: 1) the reaction of part of the $\mathrm{OH}^{-}$ions with the $\mathrm{H}^{+}$ions generated on the surface of the electrode 3 and 2) the reaction between the calcium released in the setup 
with the $\mathrm{OH}^{-}$ions to produce $\mathrm{Ca}(\mathrm{OH})_{2}$. The calcium released that reacts with $\mathrm{OH}^{-}$groups can come from: a) the decomposition of $\mathrm{CaCO}_{3}$ present in the poultice $\mathrm{PA} 2$, during the buffering of the acid $\mathrm{pH}$ at the anode and the subsequent migration of calcium to the cathode and/or b) the decomposition of $\mathrm{CaCO}_{3}$ present in the poultice $\mathrm{PC} 1$ located in the medium M4.

Using the DAC-S setup it was observed: 1) at the anode, acid $\mathrm{pH}$ values in the medium M1, which were not as extreme as those reached with the TE-A setup. This is because the potential difference between the electrode 1 hosted in this medium and the electrode 3 hosted in the medium M3 was smaller (12V in the TE-A setup, $11 \mathrm{~V}$ in the TE-C setup). In the medium $\mathrm{M} 2$, the $\mathrm{pH}$ values (ranged from 9.40 to 10.90 ) were similar in some cases to those reached with the TE-A setup and higher than those reached with the TE-C setup, because there is less decomposition of the $\mathrm{CaCO}_{3}$ present in the poultice PA2; 2) In sandstone prisms, the $\mathrm{pH}$ values were similar to those reached with the TE-C setup, below 8.7 in the area near the anode and below 10 in the area near the cathode. This is due to the lower entrance of $\mathrm{OH}^{-}$ions inside the stone; 3 ) at the cathode, the behavior was similar to that recorded in the TE-C setup, alkaline $\mathrm{pH}$ values in both media, but higher values in the medium M4 than those reached in the medium M3, due to the reasons mentioned above.

\subsection{Ion content in the poultice samples}

Table 2 shows the average amount of the anions retained in the poultices of each medium, the total average amount retained in each compartment (anode and cathode) and also the total average amount extracted from the sandstone prisms. 
In general, regardless of the setup, the anion content was higher at the anode than at the cathode and between setups the highest extraction was achieved with the DAC-S setup. The anion content in the anodic compartment was higher for the setups DAC-S and TEA than for the TE-C setup. A similar amount was extracted in the former both cases although the highest anion content in the cathodic compartment was achieved using the TE-C setup, followed by the DAC-S setup.

The greatest amount of ions mobilized were nitrates, followed by chlorides and to a lesser extent sulfates. This fact is related to the initial ion content of the sandstone prisms (content that is indicated in section 2.1).

\section{INSERT TABLE 2}

Analyzing each of the setups independently, we can see that:

1) Using the TE-A setup, most of the anions were mobilized towards the anode (more than $98 \%$ of the total), favored to a large extent by the generation of water molecules in this compartment that tends to reduce the speed of drying of the poultices PA1 and PA2, as it happened in (Feijoo et al. 2018b). Within the anode compartment, the amount retained in media 1 and 2 is practically similar in terms of chloride and nitrate. However, with respect to sulfate the results seem to indicate that the mobilization rate of this ion towards electrode 1 (effective anode of the setup) is slower. At the time of stopping the treatment the ratio of sulfate content in the medium M1 with respect to the medium M2 is very low.

The low anionic content present in the cathodic compartment can be related to diffusive and advective processes that also take place during the application of this type of treatments (Ottosen et al. 2008). 
2) Using the TE-C setup, the differences between the anion mobilized towards the anode and that mobilized towards the cathode decrease. With this setup, the total amount of anions mobilized towards the anode was about $65 \%$. Between the cathode media (M3 and M4), almost all of the anions were retained in the medium M3. This fact may be related with the preferential drying of the anode poultice PA2 due to the establishment of an electroosmotic process. When drying of this poultice occurs, the contact between the electrode 2 and the poultice PA2 begins to worsen, which affects the current flow. During this process, the importance of the electrode 3 as an anode increases, causing a mobilization of part of the anions, present in the sandstone prisms and in the medium M4, towards the poultice PC1 located in the medium M3.

3) Using the DAC-S setup, most of the anions were mobilized towards the anode $(90 \%$ of the total), as occurred with the TE-A setup. This great mobilization was achieved due to the fact that the use of the two electrodes, in the anodic compartment, allowed to maintain a certain degree of humidity during a longer period of time. However, the DAC-S setup allowed to increase the amount of anions mobilized towards the cathode ( $10 \%$ of the total). This result could be related to the potential applied in the electrode 3 that would be responsible for the high amount retained in the cathode medium M3.

\subsection{Ion content in the stone samples}

Figure 6 shows the average effectiveness percentages of the anion extraction (chloride, nitrate and sulfate) in the four parts in which each stone sample was divided.

In general, the highest efficacy (E\%-ion) in the different parts of the stone prisms were achieved with the application of the DAC-S setup. The different efficacy achieved between the setups was more pronounced in the case of chloride and nitrate and, to a 
lesser extent, in the case of sulfate. The lowest efficacy were obtained in most cases with the TE-C setup. This fact seems to be related with the drying of the poultices, mainly those located at the anode, and with the drying of the stone samples. In both cases, the drying of these materials hinders the current flow and therefore the mobilization of the anions.

Despite the differences detected between setups, the desalination efficacy reached throughout the sandstone prisms have been high, reaching in almost all cases extraction percentages above $80 \%$. This high effectiveness allows to classify the setups DAC-S and TE-A as desalination treatments as of very high efficiency, and the TE-C as a treatment of high efficiency, according to the classification established by (Zezza 2009).

\section{INSERT FIGURE 6}

In the case of the TE-A setup, the highest desalination levels, regardless of the anion, were obtained in the stone parts closest to the cathode (parts 3 and 4). This is due to the fact that, during the desalination process, the anions are mobilized from the cathode towards the anode, leaving a higher quantity of anions in this part of the stone (parts 1 and 2). The extraction percentages of chloride and nitrate were similar (approximately $92.5 \%$ in the anode area and approximately $95 \%$ in the cathode area). In the case of sulfate, the average efficacy was $90 \%$ in the anode area and $94 \%$ approximately in the cathode area.

Applying the TE-C a higher difference was observed between the efficacies reached in the anode area (lower than 90\%) and the cathode area (higher than 90\%). This fact can be related with the drying that takes place in the poultice of the anode, which hinders the mobilization and subsequent exit of the anions that accumulate in the stone parts 1 and 2 (anode areas). The extraction percentages of chloride and sulfate were similar 
(approximately $85 \%$ in the anode area and approximately $93 \%$ in the cathode area) and higher than those achieved in the extraction of nitrates.

Using the DAC-S setup, the efficacy reached for each anion throughout the entire stone prisms was similar. These extraction percentages were very high in the case of chloride and nitrate (99\%) and somewhat lower in the case of sulfate (approximately 94\%). These results indicate that the application of the DAC-S setup allows, in the same period of time as the other two setups, to reach higher and more homogeneous desalination effectiveness.

Everything commented above, regarding salt distribution into the stones and the final ion content that remain in each of the stone samples after desalination with each setup, agrees with the data provided in Table 3 in which it is appreciated that: 1) the DAC-S was the setup that allowed to reduce the ionic content to a greater extent, leaving a low anion content in the stone samples and 2) unlike what happens with the TE-A and the TE-C, the final ion content in the samples desalinated with the DAC-S setup was similar throughout the entire sample.

\section{INSERT TABLE 3}

\section{Conclusions}

The main conclusions derived from this study are:

- The DAC-S setup allows maintaining a high water content in the rock and the poultices (both compartments) which allows to maintain a good ionic contact electrode-poultice-stone.

- The high water content afforded by the DAC-S setup allows maintaining higher operation currents, which increases ion mobilization. 
- The DAC-S setup as well as the TE-C setup allow maintaining the $\mathrm{pH}$ of the rocks in the natural value, which minimizes chemical alteration. The cathode electrodes are the main responsible for this action.

- The three setups, and specially the DAC-S setup, allow to reach high percentages of ion extraction. The residual ion concentration remaining in the rock is symmetrical (anode and cathode sides) for the DAC-S setup while for the two other setups this symmetry does not exists and the results present some degree of scatter. Ion mobilization is then more homogeneous and efficient with the DACS setup.

It would be interesting evaluate in future researches, taking into account both the results achieved in this research -which confirm the suitability of the new setup- and the equations that modulate the system, if the application of equal current densities at the three electrodes will allow to desalinate any material keeping the $\mathrm{pH}$ of the different media in 7. This would allow to reduce the amount of calcium carbonate used and not have to use a buffer electrolyte which could cause color changes.

\section{Funding}

J. Feijoo work is supported by the Ministerio de Ciencia Innovación y Universidades, Spanish Government, through a Juan de la Cierva grant.

\section{References}

Asadi, A., Huat, B.B.K., Nahazanan, H., Keykhah, H.A. 2013. Theory of Electroosmosis in Soil. Int. J. Electrochem. Sci., 8, $1016-1025$.

Auras M. and J. S. Albertsen, J. S. 2008. Poultices and mortars for salt contaminated masonry and stone objects," Salt Weather. Build. Stone Sculpt., pp. 1-32. 
Bertolini, L., Coppola, L., Gastaldi, M. and Redaelli, E. 2009. Electroosmotic transport in porous construction materials and dehumidification of masonry. Constr. Build. Mater., vol. 23, no. 1, pp. 254-263.

Castellote, C., Andrade, C. and Alonso, C. 2000. Electrochemical removal of chlorides: Modelling of the extraction, resulting profiles and determination of the efficient time of treatment. Cem. Concr. Res., vol. 30, pp. 615-621.

Feijoo, J., Nóvoa, X. R., Rivas, T., Mosquera, M. J., Taboada, J., Montojo, C. and Carrera, F. 2013. Granite desalination using electromigration. Influence of type of granite and saline contaminant. J. Cult. Herit., vol. 14, no. 5, pp. 365-376.

Feijoo, J., Ottosen, L. M. and Pozo-Antonio, J. S. 2015. Influence of the properties of granite and sandstone in the desalination process by electrokinetic technique. Electrochim. Acta, vol. 181, pp. 280-287.

Feijoo, J., Matyščák, O., Ottosen, L. M., Rivas, T. and Nóvoa, X. R. 2016. Electrokinetic desalination of protruded areas of stone avoiding the direct contact with electrodes. Mater. Struct., vol. 50, no. 1, p. 82.

Feijoo, J., Ottosen, L.M., Nóvoa, X.R., Rivas, T. and de Rosario, I. 2017. An improved electrokinetic method to consolidate porous materials. Mater. Struct., vol. 50, no. 3:186, pp. 1-16.

Feijoo, J., Rivas, T., Nóvoa, X. R., de Rosario, I. and Otero, J. 2018a. In situ desalination of a granitic column by the electrokinetic method. Int. J. Archit. Herit., vol. 12, no. 1, pp. $63-74$. 
Feijoo, J., Nóvoa, X.R., Rivas, T. and Ottosen, L.M. 2018b. Enhacing the effiency of electrochemical desalination of stones: a proton pump approach. Mater. Struct., no. 51:100, pp. 1-16.

Franzoni, E. 2014. Rising damp removal from historical masonries: A still open challenge,” Constr. Build. Mater., vol. 54, pp. 123-136.

Franzoni, E., Bandini, S. and Graziani, G. 2014. Rising moisture, salts and electrokinetic effects in ancient masonries: From laboratory testing to on-site monitoring. J. Cult. Herit., vol. 15 , no. 2 , pp. $112-120$.

Grundl, T. and Michalski, P. 1996. Electroosmotically driven water flow in sediments. Water Res., vol. 30, no. 4, pp. 811-818.

Guedes, P., Couto, N., Ottosen, L. M. and Ribeiro, A. B. 2014. Phosphorus recovery from sewage sludge ash through an electrodialytic process. Waste Manag., vol. 34, no. 5, pp. 886-892.

Hansen, H. K., Rojo, A., and Ottosen, L. M. 2012. Electrodialytic Remediation of Copper Mine Tailings. Procedia Eng., vol. 44, pp. 2053-2055.

Husillos-Rodríguez, N., Carmona-Quiroga, P.M., Martínez-Ramírez, S., Blanco-Varela, M.T., Fort, R. 2018. Sacrificial mortars for surface desalination. Construction and Building Materials 173, 452-460.

Idris, A., Inanc, B. and Hassan, M. N. 2004. Overview of waste disposal and landfills/dumps in Asian countries. J. Mater. Cycles Waste Manag., vol. 6, no. 2. 
Jeon, E.-K., Jung, J.-M., Kim, W.-S., Ko, S.-H., Baek, K. 2015. In situ electrokinetic remediation of As-, $\mathrm{Cu}-$, and $\mathrm{Pb}$-contaminated paddy soil using hexagonal electrode configuration: a full scale study. Environ. Sci. Pollut. Res., 22(1), pp. 711-720.

Kamran, K., Pel, L., Sawdy, A., Huinink, H. and Kopinga, K. 2012. Desalination of porous building materials by electrokinetics: an NMR study. Mater. Struct., vol. 45, no. 1-2, pp. 297-308.

Koob, S. P., and Yee Ng, W. 2000. The desalination of ceramics using a semi-automated continuous washing station. Studies in Conservation 45(4):265-73.

Lubelli, B., and van Hees, R. P. J. 2007. Effectiveness of crystallization inhibitors in preventing salt damage in building materials. Journal of Cultural Heritage 8(3):223-34.

Lubelli, B., and van Hees, R. P. J. 2010. Desalination of masonry structures: Fine tuning of pore size distribution of poultices to substrate properties. Journal of Cultural Heritage $11(1): 10-18$.

Lubelli, B., van Hees, R. P. J. and De Clercq, H. 2011. Fine tuning of poultices: Try-outs in practice, in Salt weathering on buildings and stone sculptures: SWBSS 2011, 19-22 October, Limassol, Cyprus. Ioannou, I. and Theodoridou, M. eds., University of Cyprus, Nicosia, 381-388.

Matyščák, O., Ottosen, L.M. and Rörig-Dalgaard, I. 2014. Desalination of salt damaged Obernkirchen sandstone by an applied DC field. Constr. Build. Mater., vol. 71, pp. 561569.

Mavré, F., Anand, R.K., Laws, D.R., Chow, K.F., Chang, B.Y., Crooks, J.A. and Crooks, R.M. 2010. Bipolar electrodes: A useful tool for concentration, separation, and detection 
of analytes in microelectrochemical systems. Anal. Chem., vol. 82, no. 21, pp. 87668774.

Meng, B. 1994. Calculation of moisture transport coefficients on the basis of relevant pore structure parameters. Mater. Struct., vol. 27, no. 3, pp. 125-134.

Orellan, J., Escadeillas, G., and Arliguie, G. 2004. Electrochemical chloride extraction: efficiency and side effects. Cem. Concr. Res., vol. 34, no. 2, pp. 227-234.

Ottosen, L. M., Hansen, H. K., Ribeiro, A. B. and Villumsen, A. 2001. Removal of Cu, $\mathrm{Pb}$ and $\mathrm{Zn}$ in an applied electric field in calcareous and non-calcareous soils. J. Hazard. Mater., vol. 85, no. 3, pp. 291-299.

Ottosen, L. M., Cristensen, I. V., Pedersen, A. J. and Villumsen, A. 2005. Electrodialytic remediation of heavy metal polluted soil. Environmental Chemistry: Green Chemistry and Pollutants in Ecosystems, pp. 223-233.

Ottosen, L. M., Pedersen, A. J. and Rörig-Dalgaard, I. 2007. Salt-related problems in brick masonry and electrokinetic removal of salts. J. Build. Apprais., vol. 3, no. 3, pp. $181-194$.

Ottosen L. M. and Rörig-Dalgård, I. 2007. Electrokinetic removal of Ca(NO3)2 from bricks to avoid salt-induced decay. Electrochim. Acta, vol. 52, no. 10 SPEC. ISS., pp. $3454-3463$.

Ottosen, L.M., Rörig-dalgaard, I. and Villumsen, A. 2008. Electrochemical removal of salts from masonry - Experiences from pilot scale. Conference: Salt Weathering on Buildings and Stone Sculptures - SWBSS 2008At: Copenhagen, Denmark. 
Ottosen, L. M., Christensen, I. V., Rorig-Dalgård, I., Jensen, P. E. and Hansen, H. K. 2008. Utilization of electromigration in civil and environmental engineering--processes, transport rates and matrix changes. J. Environ. Sci. Health. A. Tox. Hazard. Subst. Environ. Eng., vol. 43, no. 8, pp. 795-809.

Ottosen, L.M. and Rörig-Dalgaard, I. 2009. Desalination of a brick by application of an electric DC field. Mater. Struct. vol. 42, no. 7, pp. 961-971.

Ottosen, L.M., Ferreira, C. M. D. and Christensen, I. V. 2010. Electrokinetic desalination of glazed ceramic tiles. Journal of Applied Electrochemistry, vol. 40, no. 6, pp. 11611171.

Ottosen, L. M. and Christensen, I. V. 2012. Electrokinetic desalination of sandstones for $\mathrm{NaCl}$ removal - Test of different clay poultices at the electrodes. Electrochim. Acta, vol. 86, pp. 192-202.

Ottosen, L. M., Christensen, I. V. and Rörig-dalgaard, I. 2012. Electrochemical Desalination of Salt Infected Limestone Masonry of a Historic Warehouse. Struct. Faults Repair, Edinburgh. Proc..

Ottosen, L. M., Kirkelund, G. M. and Jensen, P. E. 2013. Extracting phosphorous from incinerated sewage sludge ash rich in iron or aluminum. Chemosphere, vol. 91, no. 7, pp. 963-969.

Parés Viader, R., Jensen, P. E., Ottosen, L. M., Ahrenfeldt, J. and Hauggaard-Nielsen, H. 2015. Electrodialytic extraction of phosphorus from ash of low-temperature gasification of sewage sludge. Electrochim. Acta, vol. 181, pp. 100-108. 
Pedersen, A. J., Ottosen, L. M., and Villumsen, A. 2005. Electrodialytic removal of heavy metals from municipal solid waste incineration fly ash using ammonium citrate as assisting agent. J. Hazard. Mater., vol. 122, no. 1-2, pp. 103-109.

Polder, R. B. 1996. Electrochemical chloride removal from concrete prisms containing chloride penetrated from sea water. Constr. Build. Mater., vol. 10, no. 1, pp. 83-88.

Rivas, T., Feijoo, J., de Rosario, I. and Taboada, J. 2017. Use of Ferrocyanides on Granite Desalination by Immersion and Poultice-Based Methods. Int. J. Archit. Herit., vol. 11, no. 4 , pp. $588-606$.

Rörig-Dalgaard, I. 2012. Development of a poultice for electrochemical desalination of porous building materials: desalination effect and $\mathrm{pH}$ changes. Mater. Struct.. vol. 50, no. 6, p. 959-970.

Rörig-Dalgaard, I., Ottosen, L. M. and Hansen, K. K. 2012. Diffusion and electromigration in clay bricks influenced by differences in the pore system resulting from firing. Constr. Build. Mater., vol. 27, no. 1, pp. 390-397.

Sa'id-Shawqi, Q., Arya, C. and Vassie, P. R. 1998. Numerical modeling of electrochemical chloride removal from concrete. Cem. Concr. Res., vol. 46, no. 3, pp. $391-400$.

Setina, J., Krage, L., Svare, J., Kirilova, S. 2009. Simulation of desalination processes using lime based mortars, Chem. Technol. 1, 30-35.

Shan, H., Xu, J., Wang, Z., Jiang, L. and Xu, N. 2016. Electrochemical chloride removal in reinforced concrete structures: Improvement of effectiveness by simultaneous migration of silicate ion. Constr. Build. Mater., vol. 127, pp. 344-352. 
Sturm, G., Weigand, H., Marb, C., Weiß, W., Huwe, B. 2010. Electrokinetic phosphorus recovery from packed beds of sewage sludge ash: yield and energy demand. J Appl Electrochem, 40:1069-1078.

Tanaka, Y. 2007. Ion Exchange Membranes - Fundamentals and Applications, vol. 12.

Unhruh, J. 2001. A revised endpoint for ceramics desalination at the archaeological site of Gordon-Turkey. Studies in Conservation 46:81-92.

Vergès-Belmin, V., and Siedel, H. 2005. Desalination of Masonries and Monumental Sculptures by Poulticing: A Review. Restoration of Buildings and Monuments 11

(6):391-408.

Yeung, A.T. and Gu Y.Y. 2011. A review on techniques to enhance electrochemical remediation of contaminated soils. J. Hazard Mater., vol. 195, pp. 11-29.

Zezza, F. 2009. Assessment of desalination mortars and poultices for historic masonry. EU-FP6-2004-SSP-4 call. Project ID: 22714. 


\section{FIGURE CAPTIONS}

Figure 1. Scheme of the different setups evaluated in this study: DAC-S (which comprises two electrodes at the cathodic and at the anodic compartments) and TE-A and TEC setups. Four media are distinguished (M1 and M2 in the anode, and M3 and M4 in the cathode) which are filled with different poultices (PA1, PA2, PC1, PC2) in which the electrodes are inserted. DAC-S setup comprises the four media, TE-A setup comprises M1, M2 and M3 and TE-C setup comprises M2, M3 and M4 media. It is also shown the different poultice slices $(A, B, C)$ and the different parts of the stone samples $(1,2,3$ and 4$)$ in which the materials are divided for the subsequent analyses. The blue lines indicate the site where the cellulose filters are located.

Figure 2. Scheme of the different electric circuits evaluated in this study. The dashed lines show the addition necessary to apply the different setups evaluated, i.e. TE-A: media 1, 2 and 3; TE-C: media 2, 3 and 4; DAC-S: all the media. The scheme also shows the power supplies, the electrodes located in each compartment, the variable resistances (which correspond to the resistance of the stone and poultices) and a fix resistance of $1 \mathrm{k} \Omega$, in which the current intensity is registered. All of the elements connected in series.

Figure 3. Operation diagrams for the different setups evaluated in this study. a) TE-A, b) TE-C, c) DAC-S.

Figure 4. Average measurements of the total resistance (in $\mathrm{k} \Omega$ ) and the total current intensity (in $\mathrm{mA}$ ) that flows through the sandstone samples during the application of each setup.

Figure 5. $\mathrm{pH}$ measurements registered in the different parts that make up each setup (poultices slices and stone parts). 
Figure 6. Average efficacy percentage ( $n=3$ stone samples per setup) of $\mathrm{Cl}^{-}$(a), $\mathrm{NO}_{3}{ }^{-}$(b) and $\mathrm{SO}_{4}{ }^{2-}$, reached in the parts in which the stone samples were divided (parts 1 and 2 closest to the anode and 3 and 4 closest to the cathode). 


\section{Anode $1 \quad$ Anode $2 \quad$ Cathode 2 Cathode 1 \\ Electrode $1 \quad$ Electrode $2 \quad$ Electrode 3 Electrode 4}

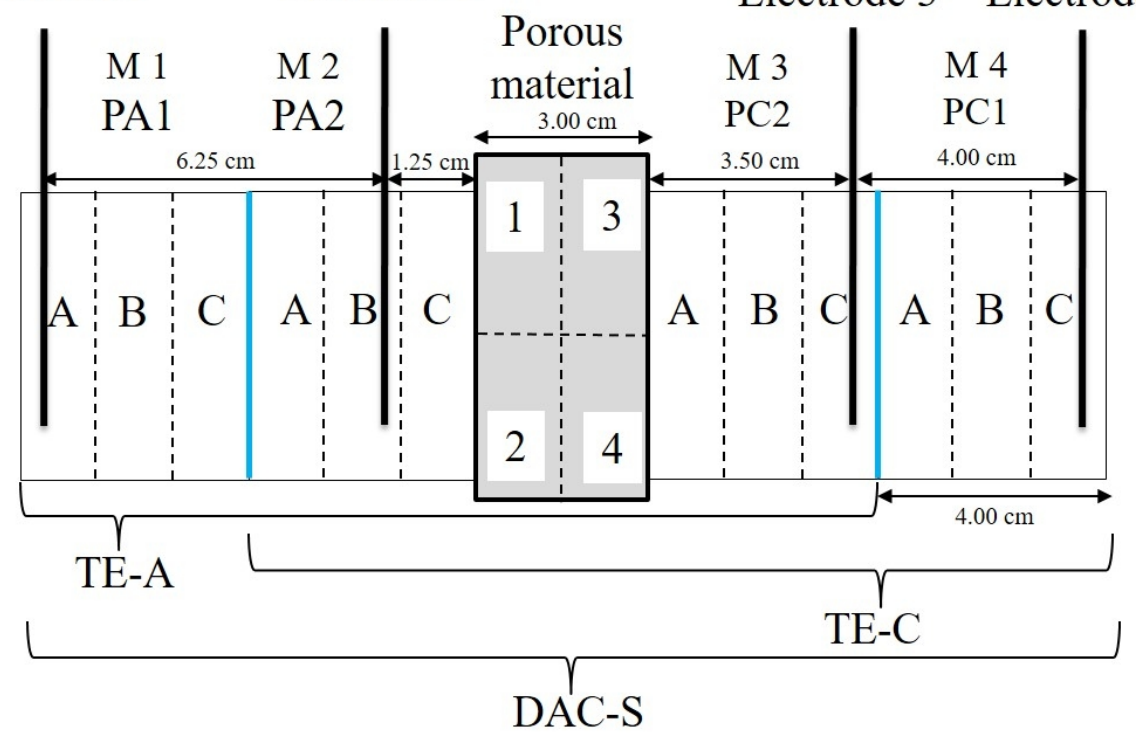

Figure 1. Scheme of the different setups evaluated in this study: DAC-S (which comprises two electrodes at the cathodic and at the anodic compartments) and TE-A and TE-C setups. Four media are distinguished (M1 and $\mathrm{M} 2$ in the anode, and M3 and M4 in the cathode) which are filled with different poultices (PA1, PA2, PC1, PC2) in which the electrodes are inserted. DAC-S setup comprises the four media, TE-A setup comprises M1, $M 2$ and $M 3$ and TE-C setup comprises M2, M3 and M4 media. It is also shown the different poultice slices (A,

$B, C)$ and the different parts of the stone samples $(1,2,3$ and 4$)$ in which the materials are divided for the subsequent analyses. The blue lines indicate the site where the cellulose filters are located.

$188 \times 126 \mathrm{~mm}(150 \times 150 \mathrm{DPI})$ 


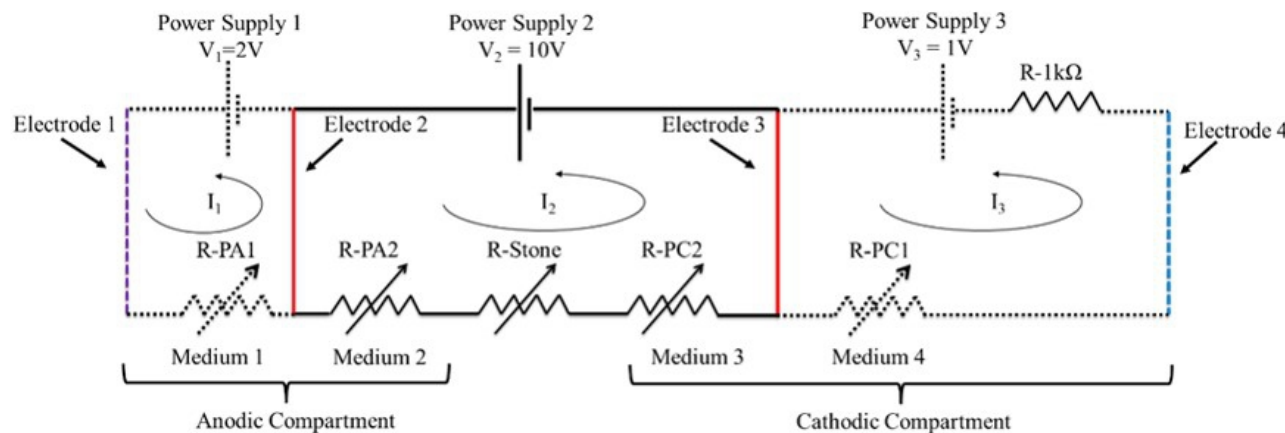

Figure 2. Scheme of the different electric circuits evaluated in this study. The dashed lines show the addition necessary to apply the different setups evaluated, i.e. TE-A: media 1, 2 and 3; TE-C: media 2, 3 and 4; DAC-S: all the media. The scheme also shows the power supplies, the electrodes located in each compartment, the variable resistances (which correspond to the resistance of the stone and poultices) and a fix resistance of $1 \mathrm{k} \Omega$, in which the current intensity is registered. All of the elements connected in series.

$312 \times 107 \mathrm{~mm}(72 \times 72 \mathrm{DPI})$ 
a) TE-A
Anode (2 V)
Anode $(10 \mathrm{~V})$
Cathode
Electrode 1
Electrode 2
Electrode 3

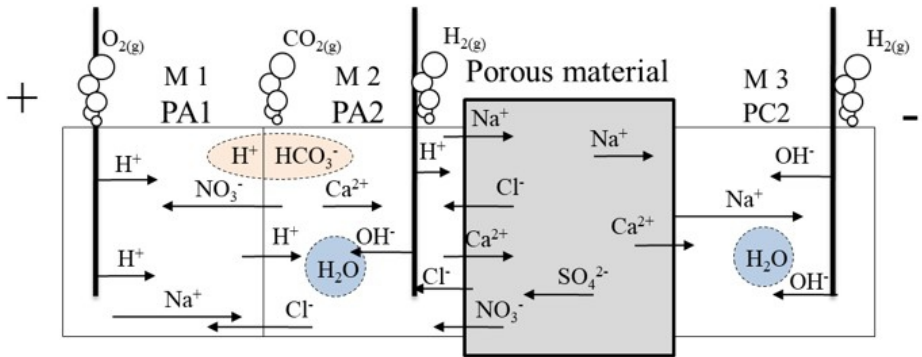

b) TE-C

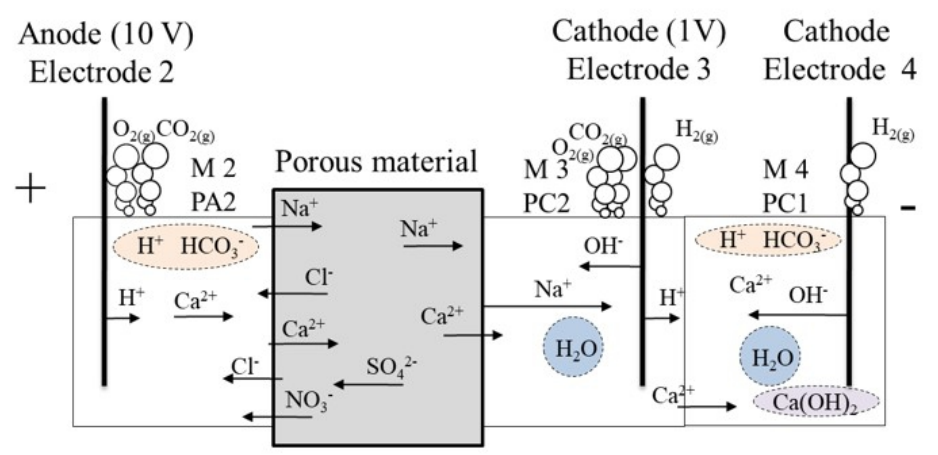

c) DAC-S

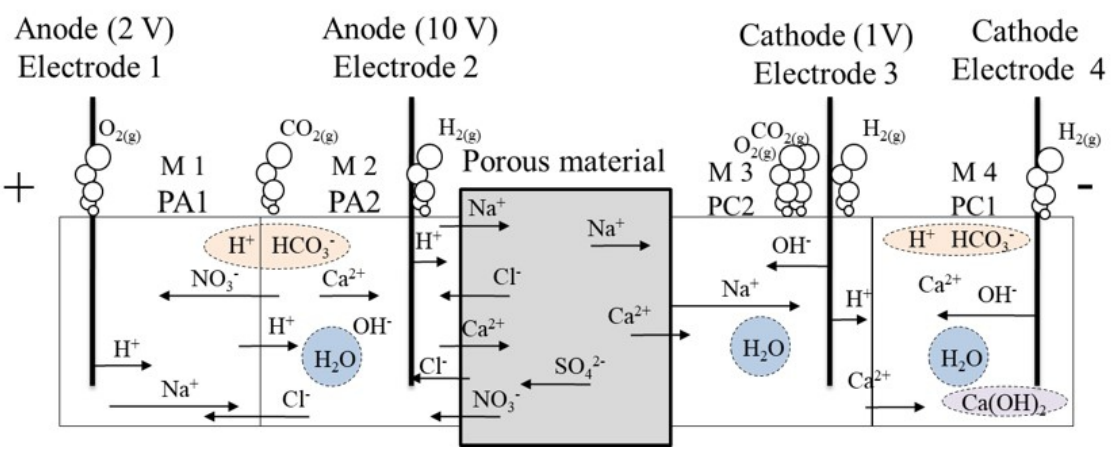

Figure 3. Operation diagrams for the different setups evaluated in this study. a) TE-A, b) TE-C, c) DAC-S. $150 \times 195 \mathrm{~mm}(150 \times 150 \mathrm{DPI})$ 

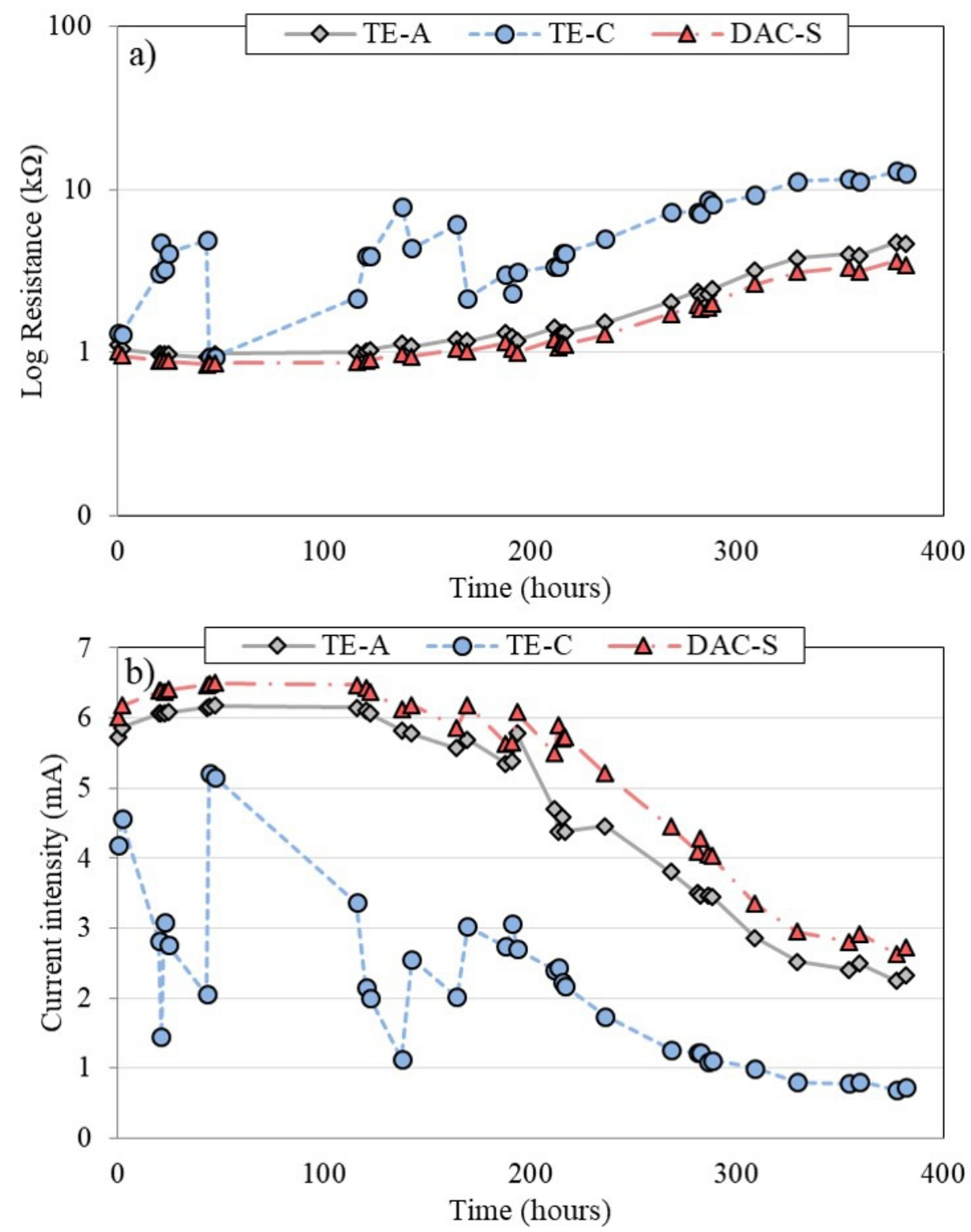

Figure 4. Average measurements of the total resistance (in $\mathrm{k} \Omega$ ) and the total current intensity (in $\mathrm{mA}$ ) that flows through the sandstone samples during the application of each setup.

$$
150 \times 187 \mathrm{~mm}(126 \times 126 \mathrm{DPI})
$$




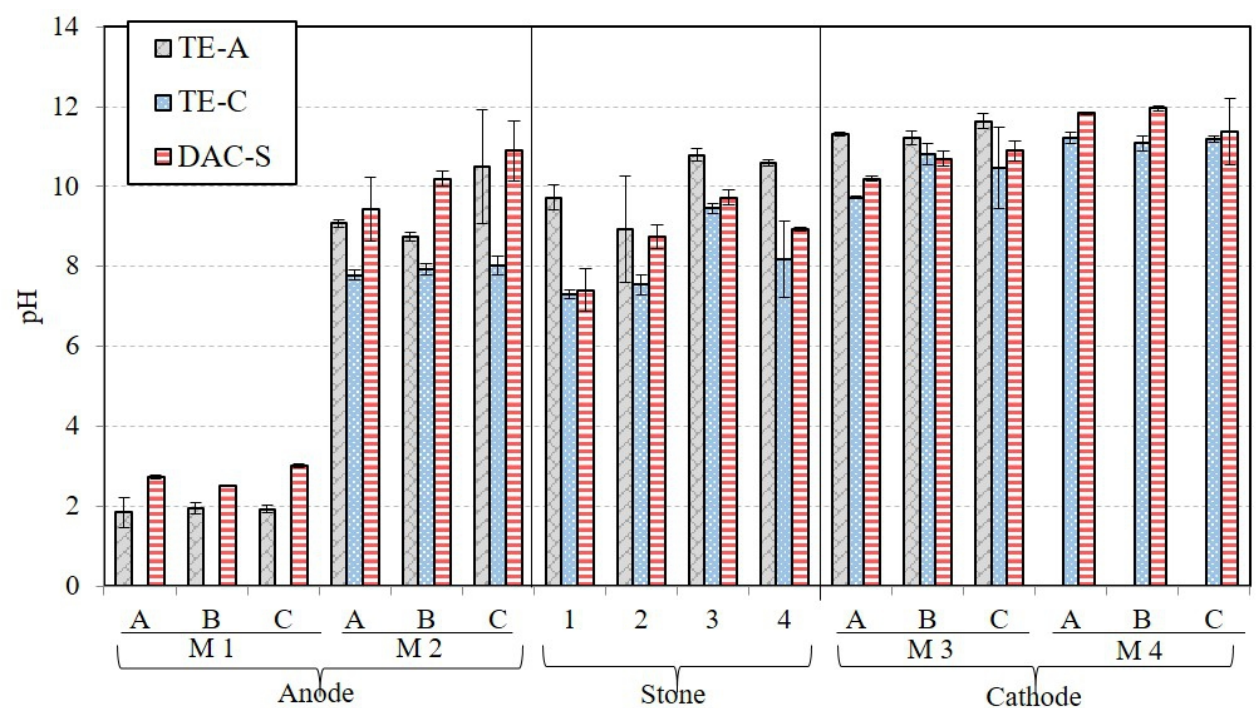

Figure 5. $\mathrm{pH}$ measurements registered in the different parts that make up each setup (poultices slices and stone parts).

$175 \times 97 \mathrm{~mm}(150 \times 150 \mathrm{DPI})$ 

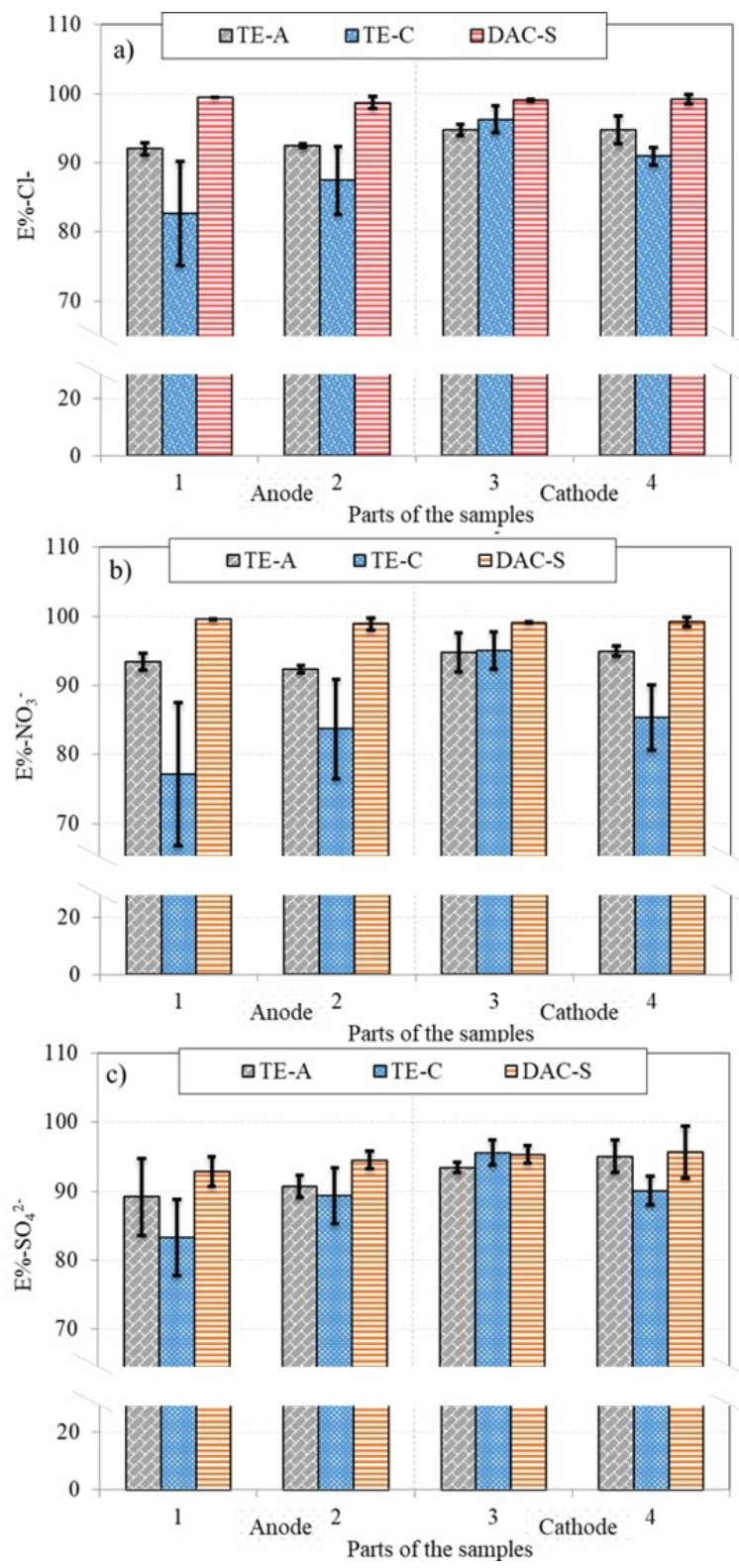

Figure 6. Average efficacy percentage ( $\mathrm{n}=3$ stone samples per setup) of $\mathrm{Cl}-(\mathrm{a})$, NO3- (b) and SO42-, reached in the parts in which the stone samples were divided (parts 1 and 2 closest to the anode and 3 and 4 closest to the cathode).

$98 \times 190 \mathrm{~mm}(150 \times 150 \mathrm{DPI})$ 
Table 1 . The average value and standard deviation of the water content (in $\% \mathrm{~g} / \mathrm{g}$ ) of the poultices used in each medium, before and after the desalination tests, and of the sandstone samples desalinated with each of the setups evaluated, at the end of the treatments. The reduction of the water content of the poultices (in \%) is also shown.

\begin{tabular}{|c|c|c|c|c|}
\hline \multirow[b]{2}{*}{ Setup } & \multirow{2}{*}{ Medium/Poultice } & \multicolumn{2}{|c|}{ Water Content in the poultice (\%) } & \multirow[b]{2}{*}{ Reduction (\%) } \\
\hline & & Initial & Final & \\
\hline \multirow{4}{*}{ TE-A } & $\mathrm{M} 1 / \mathrm{PA} 1$ & $579.35 \pm 8.15$ & $397.75 \pm 5.98$ & $31.32 \pm 0.23$ \\
\hline & $\mathrm{M} 2 / \mathrm{PA} 2$ & $41.08 \pm 0.28$ & $36.23 \pm 0.76$ & $11.80 \pm 0.38$ \\
\hline & $\mathrm{M} 3 / \mathrm{PC} 2$ & $58.78 \pm 0.38$ & $53.76 \pm 0.42$ & $8.35 \pm 2.15$ \\
\hline & & Initial & Final & Reduction (\%) \\
\hline \multirow{4}{*}{ TE-C } & $\mathrm{M} 2 / \mathrm{PA} 2$ & $41.08 \pm 0.28$ & $29.93 \pm 0.27$ & $27.38 \pm 0.33$ \\
\hline & $\mathrm{M} 3 / \mathrm{PC} 2$ & $58.78 \pm 0.38$ & $35.19 \pm 2.88$ & $40.12 \pm 4.90$ \\
\hline & $\mathrm{M} 4 / \mathrm{PC} 1$ & $41.83 \pm 0.11$ & $31.28 \pm 1.80$ & $25.21 \pm 4.30$ \\
\hline & & Initial & Final & Reduction (\%) \\
\hline \multirow{4}{*}{ DAC-S } & M1/PA1 & $579.35 \pm 8.15$ & $259.25 \pm 4.15$ & $55.25 \pm 0.72$ \\
\hline & M2/PA2 & $41.08 \pm 0.28$ & $33.06 \pm 0.01$ & $19.53 \pm 0.34$ \\
\hline & $\mathrm{M} 3 / \mathrm{PC} 2$ & $58.78 \pm 0.38$ & $47.50 \pm 1.47$ & $19.18 \pm 2.51$ \\
\hline & $\mathrm{M} 4 / \mathrm{PC} 1$ & $41.83 \pm 0.11$ & $40.37 \pm 0.51$ & $3.92 \pm 0.61$ \\
\hline \multirow{2}{*}{\multicolumn{2}{|c|}{$\begin{array}{c}\text { Final water Content in the } \\
\text { stone samples }(\%)\end{array}$}} & TE-A & TE-C & DAC-S \\
\hline & & $3.13 \pm 0.18$ & $2.83 \pm 0.23$ & $4.99 \pm 0.01$ \\
\hline
\end{tabular}


Table 2: Average amount ( $\mathrm{n}=3$ sandstone prisms per setup) of $\mathrm{Cl}^{-}, \mathrm{NO}_{3}{ }^{-}$and $\mathrm{SO}_{4}{ }^{2-}$ in $\mathrm{mg}$ retained in the different media (from M1 to M4) that constitute each setup (TE-A, TE-C and DAC-S). Total average amount retained in each compartment (Anode=M1+M2 and Cathode $=\mathrm{M} 3+\mathrm{M} 4)$. Total content extracted from the stone samples, i.e. the sum of the anode and cathode.

\begin{tabular}{|c|c|c|c|c|c|c|c|c|}
\hline \multirow{2}{*}{$\begin{array}{l}\text { Set } \\
\text { up }\end{array}$} & \multirow[b]{2}{*}{ Ion } & \multicolumn{4}{|c|}{ Ion content in each medium (mg/medium) } & \multirow{2}{*}{$\begin{array}{c}\text { Total } \\
\text { Anode } \\
\text { (M1+M2) }\end{array}$} & \multirow{2}{*}{$\begin{array}{c}\text { Total } \\
\text { Cathode } \\
\text { (M3+M4) }\end{array}$} & \multirow{2}{*}{ Total } \\
\hline & & M1 & M2 & M3 & M4 & & & \\
\hline \multicolumn{9}{|c|}{ TE-A } \\
\hline & $\mathrm{Cl}^{-}$ & $\begin{array}{c}421.55 \pm \\
55.51\end{array}$ & $\begin{array}{c}580.26 \pm 4 \\
2.51\end{array}$ & $\begin{array}{c}20.28 \pm 0 \\
73\end{array}$ & - & $\begin{array}{c}1001.81 \pm \\
13.00\end{array}$ & $\begin{array}{c}20.28 \pm 0.7 \\
3\end{array}$ & $\begin{array}{c}1022.09 \pm 1 \\
2.27\end{array}$ \\
\hline & $\begin{array}{c}\mathrm{NO} \\
3 \\
\end{array}$ & $\begin{array}{r}972 . \\
56 .\end{array}$ & $\begin{array}{c}1065.84 \pm \\
1.71\end{array}$ & $\begin{array}{c}9.76 \pm 2.9 \\
2\end{array}$ & - & $\begin{array}{c}2037.84 \pm \\
58.28\end{array}$ & $9.76 \pm 2.92$ & $\begin{array}{c}2047.60 \pm 5 \\
5.36\end{array}$ \\
\hline & $\begin{array}{l}\mathrm{SO} \\
2-\end{array}$ & $\begin{array}{c}18.81 \pm 3 . \\
94\end{array}$ & $\begin{array}{c}52.70 \pm 3.1 \\
8\end{array}$ & $\begin{array}{c}8.68 \pm 1.5 \\
2\end{array}$ & - & $\begin{array}{c}71.51 \pm 7.1 \\
2\end{array}$ & $8.68 \pm 1.52$ & $\begin{array}{c}80.19 \pm 5.6 \\
0\end{array}$ \\
\hline \multicolumn{9}{|c|}{ TE-C } \\
\hline & $\mathrm{Cl}^{-}$ & - & $\begin{array}{c}627.81 \pm 5 \\
4.00\end{array}$ & $\begin{array}{c}313.98 \pm \\
15.58\end{array}$ & $\begin{array}{c}8.14 \pm 2 . \\
65\end{array}$ & $\begin{array}{c}627.81 \pm 5 \\
4.00\end{array}$ & $\begin{array}{c}322.13 \pm 1 \\
2.93\end{array}$ & $\begin{array}{c}949.93 \pm 66 \\
.93\end{array}$ \\
\hline & $\begin{array}{l}\mathrm{NO} \\
3^{-}\end{array}$ & - & $\begin{array}{c}1125.89 \pm \\
42.27\end{array}$ & $\begin{array}{c}595.84 \pm \\
225.4\end{array}$ & $\begin{array}{c}13.14 \pm 1 \\
2.75\end{array}$ & $\begin{array}{c}1125.89 \pm \\
42.27\end{array}$ & $\begin{array}{c}608.98 \pm 2 \\
13.60\end{array}$ & $\begin{array}{c}1734.87 \pm 3 \\
07.58\end{array}$ \\
\hline & $\begin{array}{l}\mathrm{SO} \\
2-\end{array}$ & - & $\begin{array}{c}43.07 \pm 6.6 \\
6\end{array}$ & $\begin{array}{c}29.18 \pm 7 \\
32\end{array}$ & $\begin{array}{c}5.81 \pm 2 . \\
35\end{array}$ & $\begin{array}{c}43.07 \pm 6.6 \\
6\end{array}$ & $\begin{array}{c}34.98 \pm 9.6 \\
7\end{array}$ & $\begin{array}{c}78.05 \pm 3.0 \\
1\end{array}$ \\
\hline \multicolumn{9}{|c|}{ DAC-S } \\
\hline & $\mathrm{Cl}^{-}$ & $\begin{array}{c}421.00 \pm \\
22.63 \\
\end{array}$ & $\begin{array}{c}620.01 \pm 4 . \\
26 \\
\end{array}$ & $\begin{array}{c}103.03 \pm \\
31.37 \\
\end{array}$ & $\begin{array}{c}11.91 \pm 1 \\
.68 \\
\end{array}$ & $\begin{array}{c}1041.01 \pm \\
18.37 \\
\end{array}$ & $\begin{array}{c}114.94 \pm 3 \\
3.06 \\
\end{array}$ & $\begin{array}{c}1155.95 \pm 5 \\
1.43 \\
\end{array}$ \\
\hline & $\begin{array}{c}\mathrm{NO} \\
3 \\
\end{array}$ & $\begin{array}{c}890.10 \pm \\
11.81 \\
\end{array}$ & $\begin{array}{c}1134.23 \pm \\
80.32\end{array}$ & $\begin{array}{c}187.42 \pm \\
15.57 \\
\end{array}$ & $\begin{array}{c}17.18 \pm 2 \\
.17 \\
\end{array}$ & $\begin{array}{c}2024.33 \pm \\
68.51\end{array}$ & $\begin{array}{c}204.60 \pm 1 \\
7.75\end{array}$ & $\begin{array}{c}2228.93 \pm 8 \\
6.26\end{array}$ \\
\hline & $\begin{array}{c}\mathrm{SO}_{2-} \\
4-\end{array}$ & $\begin{array}{c}13.62 \pm 2 . \\
29\end{array}$ & $\begin{array}{c}59.99 \pm 4.3 \\
3\end{array}$ & $\begin{array}{c}13.11 \pm 2 \\
67\end{array}$ & $\begin{array}{c}3.21 \pm 0 . \\
69\end{array}$ & $\begin{array}{c}73.61 \pm 2.0 \\
5\end{array}$ & $\begin{array}{c}16.32 \pm 3.3 \\
6\end{array}$ & $\begin{array}{c}89.93 \pm 5.4 \\
1\end{array}$ \\
\hline
\end{tabular}


Table 3. Final average anion content and standard deviation $(n=3$ stone samples per setup) of $\mathrm{Cl}^{-}, \mathrm{NO}_{3}{ }^{-}$and $\mathrm{SO}_{4}{ }^{2-}$ (in $\mathrm{mg} / \mathrm{g}$ ) retained in the parts in which the stone samples were divided (parts 1 and 2 close to the anode and 3 and 4 close to the cathode) after the desalination treatment with each setup (TE-A, TE-C and DAC-S). The total average amount of each anion (in $\mathrm{mg} / \mathrm{g}$ ) retained in samples desalinated with each setup is also shown.

\begin{tabular}{|c|c|c|c|c|c|c|}
\hline \multirow{2}{*}{ Setup } & \multirow{2}{*}{ Ion } & \multicolumn{4}{|c|}{ Part of the stone sample } & \multirow{2}{*}{ Average } \\
\hline & & 1 & 2 & 3 & 4 & \\
\hline \multirow{3}{*}{ TE-A } & $\mathrm{Cl}^{-}$ & $19.38 \pm 2.43$ & $12.54 \pm 1.54$ & $10.32 \pm 1.69$ & $11.82 \pm 4.87$ & $13.51 \pm 4.34$ \\
\hline & $\mathrm{NO}_{3}^{-}$ & $21.71 \pm 4.39$ & $17.14 \pm 0.27$ & $13.98 \pm 7.58$ & $15.45 \pm 2.90$ & $17.07 \pm 4.67$ \\
\hline & $\mathrm{SO}_{4}^{2-}$ & $2.25 \pm 1.12$ & $1.33 \pm 0.11$ & $1.11 \pm 0.13$ & $0.97 \pm 0.48$ & $1.41 \pm 0.71$ \\
\hline \multirow{3}{*}{ TE-C } & $\mathrm{Cl}^{-}$ & $33.26 \pm 14.53$ & $28.72 \pm 11.21$ & $14.50 \pm 7.76$ & $25.68 \pm 3.54$ & $25.54 \pm 10.64$ \\
\hline & $\mathrm{NO}_{3}^{-}$ & $83.25 \pm 37.66$ & $70.93 \pm 31.12$ & $37.00 \pm 20.23$ & $78.95 \pm 25.27$ & $67.53 \pm 29.47$ \\
\hline & $\mathrm{SO}_{4}^{2-}$ & $2.49 \pm 0.82$ & $1.90 \pm 0.72$ & $1.35 \pm 0.57$ & $2.20 \pm 0.45$ & $1.98 \pm 0.67$ \\
\hline \multirow{3}{*}{ DAC-S } & $\mathrm{Cl}^{-}$ & $1.38 \pm 0.15$ & $2.12 \pm 0.16$ & $2.02 \pm 0.60$ & $2.20 \pm 0.77$ & $1.93 \pm 0.51$ \\
\hline & $\mathrm{NO}_{3}^{-}$ & $2.42 \pm 0.62$ & $3.23 \pm 0.26$ & $3.80 \pm 0.81$ & $4.19 \pm 1.11$ & $3.41 \pm 0.92$ \\
\hline & $\mathrm{SO}_{4}^{2-}$ & $1.48 \pm 0.11$ & $0.85 \pm 0.46$ & $0.85 \pm 0.34$ & $0.88 \pm 0.35$ & $1.02 \pm 0.38$ \\
\hline
\end{tabular}

